\title{
Theosis and Kenoticism in Contemporary Vampire Series
}

\author{
Stephanie Solywoda \\ Oxford University, Oxford, UK
}

\begin{abstract}
This article mainly tells something about Theosis and Kenoticism in Contemporary Vampire Series. Theosis, or divinization, refers to the infinite process of self-perfection that is the basis of Christian life. Kenoticism, or "self-emptying”, describes the imitation of Christ's humility. Exploring the human-vampire relationship in light of these ideas reveals the implicit Christian underpinnings of and approach to morality in these series.
\end{abstract}

Keywords: theosis, kenoticism, vampire

\section{Introduction}

Among recent portrayals of the undead, vampires are perhaps the most morally ambiguous. No longer "the earthly embodiment of supernatural Evil”, the contemporary vampire has become a person and, as a consequence, has also developed a conscience. This is especially the case in vampire romances where male vampires fall in love with female humans, who then quest to help redeem their vampire lovers. Often this mission involves saving the vampire's supposedly-lost "soul” and quenching his blood thirst, even if this endangers the female protagonist. This theme is apparent in some of the most popular serialized vampire narratives of today, namely the stories about Buffy the Vampire Slayer and her world; the novel and film versions of the Twilight saga; and the popular television series The Vampire Diaries and True Blood, along with the novels upon which these series are based.

The romantic storylines in these serialized narratives depend predominantly on the redemptive aspects of love. Within the romance between human and vampire, the characters strive to better themselves, giving rise to issues of redemption, salvation and willing sacrifice. Like Western popular culture in general, these stories depend on an essentially Christian set of values, although they may be difficult to pin-point specifically since vampires are rarely explained in explicitly Christian terms. More often these series use the terms "good", "bad" and "evil" in a general sense.

Nevertheless, examination of the human protagonists' self-sacrificing love and how vampires are integral to the plot's moral aspects offers rich rewards for theological speculation; within these stories aspects of both the concepts of theosis and kenoticism are found. Theosis, or divinization, refers to the infinite process of self-perfection that is the basis of Christian life. Kenoticism, or "self-emptying", describes the imitation of Christ's humility. Exploring the human-vampire relationship in light of these ideas reveals the implicit Christian underpinnings of and approach to morality in these series.

Stephanie Solywoda, Oxford University.

Correspondence concerning this article should be addressed to Arcadia Desk, 16-17 Turl Street, Oxford OX1 3DH. Email: ssolywoda@hotmail.com. 


\section{Supernatural Morality}

By their very nature supernatural series they are exaggerated. They are likely to include characters that appear either purely good or purely evil. Absolute characters can reassure audiences, especially those who seek morally sound resolutions to the romantic plot. However, the characters' ethical standpoints may only appear concrete. Upon closer examination, it becomes clear that moral ambiguity often increases as the story progresses. Rather than providing readers with a reassuring world, the plots move from an absolute framework to a more relative, ambiguous, even existential, view of life. Vampire series, especially, have come to depend on plots that both confirm and challenge absolute notions of good and evil. Yet, as the frequent appearance of theosis and kenoticism discussed below suggests, greater ambiguity does not necessarily challenge the Christian themes in these stories.

Unlike Dracula, described as an "arrow in the side of Him who died for man", the contemporary vampire is inherently ambiguous . Harboring bloodthirsty monsters within, and these vampires look and act like humans. Despite this "ambiguous self", the vampire still tends to be identified as a "fallen" creature in the implicit Christian mythos of Western culture.

Since vampires are not directly addressed by theology, whether they are considered human enough to live by human moral codes is open to interpretation within these narratives. Vampires can reject parts of the human condition (such as guilt) and strive to uphold other parts. Since they do not have to judge themselves according to human-made morality unless they want to, it is interesting that contemporary vampire characters do. How to be a good person is a central question in these stories. Vampire-human relationships escalate the conflict between a vampire's "humanity" and his inner-monster.

The struggle to be and do good is present in all the vampire narratives discussed here and the popularity of this theme with creators and fans suggests that moral conflicts resonate within most, if not all, of them. Interest in and sympathy for vampires can also be understood as a reflection of the anxiety modern individuals who suffer in a world absent of clear-cut absolutist morality. This perplexing state has been identified and labelled both by modern philosophers and theologians. Just as vampires struggle to make sense of themselves as beings in this world, so do they.

The supernatural context allows these battles to be fought on a grander scale than a more realistic setting would permit. Even though in "real life" morally ambiguous situations must constantly be dealt with, these situations can seem unclear. In supernatural fiction readers and viewers can watch and read about exaggerated versions of similar struggles, potentially helping fans situate themselves ethically. Vampire narratives encourage their audiences to question a host of ideas about good and evil that might not have been easily approachable in everyday life.

\section{Theosis and the Vampire}

Although being a vampire is associated with damnation, none of the vampires in these stories have willingly become damned. It is important to think of the male vampire lovers in Buffy the Vampire Slayer, The Vampire Diaries, the Twilight saga and True Blood as men born into a state of sin through no conscious choice of their own and ever after seeking a state of grace. In this way vampires act as "metaphors" for the sinful nature of man, and therefore become compelling subjects of theological consideration (Clements, 2011, p. 62). 
Theosis, in Christian thought, is a transformative process by which the human being can approach God. To participate in this process is to redeem the fallen nature of man and realize the divine aspects of humanity. Although the potential for grace is a God-given part of human nature, theosis emphasizes the participation of the human subject in his own salvation. The fact that seeking redemption characterizes these vampires' personalities and storylines therefore recalls theosis.

Not all vampires in the stories discussed here participate in a struggle to better themselves; such a search typically sets one vampire apart from the rest in the series. These special individuals must try to save a twice-damned soul, to overcome humanity's sinful nature and defy their vampire nature.

Vampires seek redemption through demonstrative acts, just like normal people do. An important question sets vampires apart from humanity though: Can vampires ever redeem themselves? Although they look it, vampires are not fully human and the hope of salvation offered in Christ's incarnation is seemingly restricted to humanity alone. The vampire's struggle makes for compelling drama because of this mystery; the audience simply does not know whether redemption is possible.

Distinct narrative devices can indicate the "humanity" of a given vampire, and therefore very effectively highlight the problems of salvation. Such devices are most apparent when a vampire's ability to be redeemed is signified by a state or material condition: In Buffy the Vampire Slayer vampires can lose and regain "souls" and in The Vampire Diaries they can turn their "humanity" on and off at will, described as switching a mental button. In these two series the "soul" and "humanity" are codes for conscience or "emotional self". Studying these devices helps explore what makes a vampire worthy of salvation, since it seems obvious that merely to be human does not guarantee moral goodness. In fact, humans in these series are just as likely to "be bad" or make mistakes. The key difference is that humans are fundamentally worthy of forgiveness, and vampires are not.

In Buffy the Vampire Slayer the "soul" plays an important part in the redemption of two main vampires, Angel and Spike. Angel has regained his "soul” through a curse and is tortured by memories of the cruel acts he committed in his "soulless" state. The fact that the curse of his soul was designed to torture him, and not to offer him the possibility of salvation, resonates with philosophy that has labelled the anxiety of the human condition as a matter of consciousness. Unbeknownst to Angel, the curse will be lifted when he has a moment of pure happiness and such happiness is achieved when he consummates his relationship with the female protagonist, Buffy, in season.

It is possible for Angel's soul to implanted and removed many times because magic causes his transformations in this series. Even though Angel's moral consciousness was granted as punishment, he uses his soul and embarks on a journey of theosis. The loss of his soul makes Angel an indifferent, cruel monster. Significantly, without his soul his journey of salvation is suddenly meaningless to him. This change in Angel's priorities exemplifies how theosis can only occur when the person is conscious of his sinful state and truly willing to change it.

Angel eventually gets his soul back, but the ordeal of its loss and return leaves him unsure of why he is still on earth. He is once again tortured by his past and the need to establish his true nature. In the episode “Amends” Angel's struggle is complicated by the interference of the spirit "The First Evil”, who appears before Angel in guises of his former victims. His victims enable recollections that pin-point exactly wherein his sin lies. As a result, Angel is unsure about the source of his potential to do evil, finally concluding that "It's not the demon in me that needs killing... It's the man”. His state of anxiety is because he knows that his character is weak and drawn to temptation, not because he is a vampire. 
Angel's desire to give in to temptation is illustrated in this episode by an analogy between the happiness he felt when making love to Buffy and Jesus' temptation in the garden of Gethsemane before his crucifixion. Angel hallucinates being back in Buffy's arms, giving up his soul in exchange for another moment with Buffy and escaping from the consciousness that informs his daily struggles to better himself. He cannot ignore the realization that part of him wants to give in, even if "The First Evil" has brought this realization to pass because, as Angel explains, this is a truth about himself: "I want you so badly! I want to take comfort in you, and I know it will cost me my soul, and a part of me doesn't care”. This admission shows Angel's insecurity about his moral strength. Even with a soul, he must resist his own desires in order to save himself and the world. Having a soul is only the beginning of theosis for a vampire seeking redemption.

The vampire Spike offers another perspective on this journey. He has been captured and implanted with a micro-chip that prevents him from hurting humans. Spike still has his evil vampire nature, but it is neutralized because he cannot act on it. Even "neutralized”, Spike’s behaviour is unreliable and haphazard and Buffy, still believing that his true nature is evil, refuses to completely trust him. This does not stop Spike from slowly learning, in a "behavioralist" psychological way, to do good and please the high-minded heroes of the series.

Spike's path may seem psychological or scientific, rather than spiritual, but his slow learning of right and wrong ultimately leads him to choose his soul. Unlike Angel, Spike's "soul” is not a curse inflicted upon him. Spike actively seeks his soul out through dangerous and painful trials. He also differs from Angel whose moral state is involuntary, because, whether he has his soul or not, Spike's morality is not always absolute. When Angel is good, he is really good, and the same is true when he is bad. Precisely because Spike is never under a magic curse, he only slowly becomes good while continuing to act impulsively or selfishly. These imperfections suggest to the audience that Spike is more "human" than Angel.

At the end of the series Spike appears the more Christ-like than Angel ever does, suggesting that through his moral struggles Spike comes closer to theosis than Angel. In the episode "Beneath You", the scene where Spike finally admits he has a soul amply demonstrates his correlation to Christ. This scene takes place in a church, and Spike is only able to tell the truth about his soul while walking along the Stations of the Cross, connecting his struggles to Jesus' final journey to crucifixion. Spike also communicates how he feels about the soul in mock-biblical language. The final moments of the scene have the most compelling Christian tableau: Spike lays his body on a large cross at the church's altar and it begins to smoulder from the contact, symbolizing a culmination of his walk to the cross. As he tortures himself in this way, Spike asks "Can we rest?" implying weariness from carrying the burden of his supposedly-damned soul.

Angel and Spike exemplify the hardships involved in theosis: Each vampire must master a part of himself and truly try to be a better being than he has been allotted in death. In Buffy the Vampire Slayer, the will of the vampire has a central role in vampiric theosis, although it must be aided by outside forces like luck, curses and micro-chips.

In The Vampire Diaries greater emphasis is placed upon will alone by stressing each vampire's choice of "humanity". In this series the question of "turning on" humanity is a more involved process than the addition of a soul is in Buffy the Vampire Slayer. The device of "humanity" can be understood by looking at the internalized and externalized moral struggles apparent in the contrast between the behaviours of two vampire brothers, Stefan and Damon. Initially, these vampires might seem to have been modelled on Angel and Spike from Buffy the Vampire Slayer, but the former must develop their humanity for themselves without the magical aid of a "soul". 
Both brothers in The Vampire Diaries demonstrate a good side and an evil side. Their kinder nature results from turning on their "humanity", a device introduced at the end of the first season that becomes more apparent and important as the series progresses. The audience learns about this important aspect of vampire mythology through peripheral characters who explain that vampires “...don't have to feel pain... they could turn it off if they shut out their humanity”. Damon confirms this lore, pessimistically adding that to do so does not make life any easier. In other words, turning off "humanity" is not as straightforward as Angel's sudden absence of "soul".

For these brothers "humanity" is always within, and they could tune into this part of themselves at any time. The result, however, is internal moral conflict: the good in Stefan wars with the evil in him and the evil in Damon likewise, giving each brother the potential to be his own contradiction. These two characters also contrast with each other. Seemingly, whenever one brother becomes evil, the other turns good. Circumstances have allowed the poles on this antimony to shift over the years, allowing both characters the opportunity to sin and to approach salvation. The contrast between Stefan and Damon is not pure, though, they have very different personalities. Together they demonstrate the device of "humanity" in all of its forms, turned on, off and in transition between extremes.

Through the control that the brothers exert over their humanity, The Vampire Diaries explores the notion of "will" and redemption. To a large extent, the series focuses on the question of will: In addition to willing "humanity" vampires also can compel humans and weaker vampires to act against their own will. The ability to compel others seems "evil", but is sometimes used for good. However, the series quickly establishes that compulsion takes advantage of the compelled and eliminates the possibility of a reciprocal, redemptive relationship.

These two devices, "humanity" and compulsion, collude against Stefan when he is compelled to turn off his "humanity" in season. It remains to be seen whether Stefan will reassert his humanity on his own or the compulsion will be broken by the vampire who compelled him. With the addition of compulsion, neither Stefan nor Damon can be considered true masters of their vampire natures, and even though will have a greater impact on their behaviour than it has on the vampires in Buffy the Vampire Slayer.

The best example of the unadulterated power of vampire-will is the vampire Edward in the Twilight saga. When they first meet him, he is already a self-avowed "vegetarian" vampire, meaning that he has chosen to feed on animal rather than human blood to sustain himself. In Twilight, the first scene of the saga, Edward struggles with his vampire nature because of the particularly intoxicating effect that his human love interest, Bella, has on him. The first time he senses Bella, Edward can hardly stop himself from killing her; this uniqueness makes her especially attractive to him. The thrill of desire, expressed as the irresistible call of her blood, is resolved through will alone. Edward discovers that with forbearance (and much straining of the jaw on the part of Robert Pattinson, the actor who portrays this character on film), he can spend more time in Bella's company and immunize himself against the scent of her blood.

While Edward's theosis promises to be the most significant, because it is the most "self-lead", the opposite is actually true. His progress is less compelling than that of the other male protagonists discussed here because of the absence of praxis in his narrative. The narrative takes place strictly from Bella's point of view, making it nearly impossible to empathize with Edward's inner struggle. Edward's theosis is also less persuasive because it depends on will alone. This defies the conventions of theosis, where human effort must be accompanied by God's love to result in transcendence. 
Another reason why Edward's story is less compelling is because Twilight takes place in a world with a rigid moral structure that prevents the narrative from becoming too complex. When the vampire's struggle takes place in a morally ambiguous setting, the dramatic and emotional potential runs higher; a prime example is the diversity of motives and morals in The Vampire Diaries. Damon's moral struggle is more complex due to its morally ambiguous setting, much as Spike's struggle is in Buffy the Vampire Slayer. Both of these characters constantly fight their inner vampire nature and struggle to become good without the assurance of sudden conversion; unlike Angel and Stefan, whose evil sides can be brought about against their will; and unlike Edward, whose will is absolute, their will is imperfect, their conversion to good is less reliable, and their fight to be good therefore is so much more compelling to watch.

\section{Kenoticism and Redemptive Love}

Human's love interests support attempts at theosis made by the vampires discussed above. These women can be considered characters of "faith", since a defining feature of their characterization is faith in their vampire's ability to overcome his inner monster. From the perspective of readers and viewers, the humans in these stories seem to act better than practically any real-life woman. These fictional women share saint-like qualities, act as role models, and their forbearance in the face of violence is controversial among critics. Despite differences in characterization they have a willingness to deny themselves for the betterment of others in common. In light of the theosis apparent in these narratives, it therefore seems prudent to also explore the kenoticism, or self-emptying of will, exhibited by the women in the series, as a contrast to the will manifested by the male characters. Whereas the vampires demonstrate theosis through praxis, their women approach Christ through the model of sacrifice.

A near-perfect example of such self-sacrifice comes from the Twilight saga. The protagonist Bella emulates a mythical figure called the "third wife" introduced in Eclipse, the third instalment of the saga. In the novel and the film, the legend of a Native-American wife who saves her husband from a vampire by distracting it the only way she can, with her own spilled blood, fascinates the physically weak Bella. This story inspires her because she cannot protect the person she loves. In the final battle, Bella follows the example of the third wife and stabs herself in order to draw attention from Edward, who is under attack by another vampire.

In The Vampire Diaries, the female protagonist Elena also embraces sacrifice. She learns that her death is essential to an important ritual. This ritual is not in her interests, but she accepts the necessity of her own death because she wishes to protect her friends and family. Unlike Bella and Elena, Buffy actually does sacrifice herself in Buffy the Vampire Slayer in the episode "The Gift". She realizes that the only way to avert the apocalypse and save her sister is to die in her sister's place.

All of these women are willing to think in terms of creation through denial of themselves, and particularly when their families are in jeopardy. More interestingly, this self-denial plays a role in their relationships with the vampires in their lives. They amply demonstrate how being the beloved of a killer is to welcome danger and death. These women, under the auspices of their relationships, allow the violation of their person in both the traditional sexual sense and the metaphorical violation that is the vampire bite.

In True Blood and The Vampire Diaries sharing blood between partners is part of a human-vampire romantic relationship and significantly Sookie, the female protagonist of True Blood, and Elena are also both in active sexual relationships with their vampire boyfriends. Sookie uses her blood to heal her vampire boyfriends and Elena insists that Stefan drink her blood when she realizes that his abstinence has seriously weakened him. 
In Sookie's case, blood and sex are casually shared in a way that corresponds to her forgiving character. Sookie does not judge her vampire partners, Bill and Eric, for having different needs than a human boyfriend.

In Buffy the Vampire Slayer, Buffy, though sexually involved with Angel and Spike, does not causally share blood with either of them. She does feed them in two significant moments: Angel feeds off of her deliberately in "Graduation Day: Part One” and in "Sleeper” Spike licks Buffy's open wound. When Angel drinks Buffy's blood the physical relationship between them, which has been constrained because their lovemaking is literally his moral undoing, is consummated in the blood exchange and this is a moving experience for both of them. In "Sleeper", Spike cannot to remember whether he has begun to kill humans again, but with one taste of Buffy's blood all of his memories and moral conscience return to him in a rush. In both instances Buffy feeds these vampires against her will, but having done so the exchange of blood has a profound and life-saving effect on them.

Like Buffy and her beaus, Bella and Edward have a strong romantic relationship without sexual acts. Unlike Buffy, Bella insists on putting herself into Edward's life. Bella is sure that a romantic relationship between a vampire and a human is possible, and it is Bella who wishes to spend a lot of time with Edward, even though he finds her almost as appealing as a meal as a girlfriend.

Clearly these women are willing to sacrifice themselves and are willing to allow their partners to prey upon them to a certain extent-what is less straight forward is the redemptive effects of this willingness on their beloveds. In The Vampire Diaries and Buffy the Vampire Slayer, Elena and Buffy's love demonstrates a means of redemption for the vampires in their lives.

In The Vampire Diaries vampires can act like loving normal people when their "humanity" is turned on. From the point of view of vampire rehabilitation, Stefan and Damon are more able than most to live normally, especially because they can walk in the sunlight, and therefore Elena's hopes for a normal relationship with Stefan are perhaps the least ambitious of all of the heroines' discussed here. Stefan has turned on his humanity and he and Elena are able to be in a normal romantic relationship. Stefan might worry that his presence endangers Elena, but she convinces him that even without vampires she would still be in danger, so he is worth her love.

Stefan's worthiness of Elena's love is called into question in the beginning of Season because he turns off his humanity. Elena's reaction shows that it is not a turned on "humanity" that makes a vampire worthy; she does not shift her allegiance to Damon who seems to have turned his "humanity" on. Instead Elena uses Damon's rehabilitation as a basis for faith that Stefan can be brought back. Indeed Damon's story is a sign that both brothers can be saved by love, as demonstrated by the season 1 finale which shows that Elena has already helped save Damon. At the end of this episode Damon tells a woman he thinks is Elena.

"You know, I came to this town wanting to destroy it. Tonight I found myself wanting to protect it. How does that happen? I'm not a hero, Elena. I don't do good. It's not... in me... somewhere along the way, you decided that I was worth saving. I wanted to thank you for that.”

Damon's hope to be worthy of Elena's love, and his love for her, has lead him to eventually embrace his humanity. Stefan's redemption seems a less clear path. In “Ordinary People”, Elena tells Damon that Stefan's love for his brother, not his love for her will, redeems him.

Buffy, like Elena, also plays a role in the salvation of her two vampires' love interests. Buffy resigns herself to the possibility that she may have to kill evil soulless Angel, but as soon as he has his soul again, 
despite no longer having a physical relationship with him, she begins to defend him and support him. In "Amends" this support reaches its apex. A wider theme of the episode is forgiveness as Buffy overcomes her anger at Angel's past misdeeds in order to be able to help him. In this episode she tries to convince him that his life is not a waste and that he still can redeem himself, saying "If I can't prove you belong in this world than I do not know what can”. In this statement she takes personal responsibility for his salvation, assuming it is her job to care for him, protect him, and help him see the value of his life. Angel has given up on herself and set out to commit suicide as the sun rises. He cannot be convinced to live by Buffy alone, when, to both of their amazement, the weather miraculously turns snowy and no sun rises that morning. Both characters interpret this as a sign from a "higher power" that Angel should not commit suicide.

Spike's redemption through his love for Buffy is far more clear-cut. Until Season 6, Angel is the only vampire with a soul in this narrative. This fact is repeatedly emphasized as the reason why Buffy is able to support Angel and make allowances for his failings that she would not do for another vampire. Throughout seasons 5 and 6, Spike's love for Buffy motivates him to do good acts, such as helping the helpless and fighting evil, even though he has no soul. Love, rather than magic or mystery, is the cause for Spike's theosis. This progression culminates in "Grave", the season 6 finale, when Spike goes through physical trials in order to "be the kind of man". Buffy deserves and gets his soul.

As with Angel, having a soul is only the first step of Spike's continuing struggle for redemption. If Spike's attainment of a soul was not enabled by Buffy, she certainly stands by him throughout season 7 once he has one, defending him to those who doubt, "he can be a good man", and trusting him to fight by her side.

Spike is able to be redeemed because Buffy, risking her own safety, allows him to participate in redemptive acts. In season 7 he develops enough, that he can believably sacrifice himself in order to save Buffy and the world in the series finale.

Elena and Buffy stand by their men, even when the redemptive storyline is not clear. The salvation of these characters is beset by all manner of problems that further facilitate the vampires' journey of theosis. The vampires are never truly rewarded, even when they do the right thing. For example, Angel, despite trying his best to be good, seems to lose his comrades in arms at an alarming rate. Likewise Spike, despite attempting to save the world three times, always finds the sacrifices he has made to be in vain. Stefan and Damon are rewarded for their help to the people of Mystic Falls with reversals of fortune, new sets of rules and new evil nemeses to defeat. The seemingly endless extension of their struggles suggests that road to redemption will be difficult no matter how much help or care they receive from the women in their lives.

The case of Bella and Edward in the Twilight saga is a good example of the ambiguity of who is helping whom in the loving relationship. Edward is convinced that he is damned, and in New Moon, the second instalment of the saga, Edward chooses to leave Bella rather than subject her to a lifetime with him for a partner. On the other hand, Bella is convinced that Edward is worth saving, that vampires are good, and that Edward's belief that he has no soul is misinformed. Even so, Edward himself is ashamed of his nature and the acts like he committed as a young vampire. When Bella herself demonstrates that all new vampires need not succumb to bloodlust, in Breaking Dawn when she becomes a vampire, the possibility of a victimless transition confirms her own conviction that vampires are not inherently evil. The extent to which Bella ultimately saves Edward is debatable, though (after Edward leaves in New Moon Bella is listless and practically gives up on life) raising the possibility that, in this case, their love for each is the salvation of the both of them.

Sookie's relationships also do not demonstrate a straightforward redemption of her beloved, although it is 
not for her lack of trying. Sookie generally lets Bill, and later her love interest Eric, takes comfort in her both in terms of sex and sustenance, but as the narrative progresses Sookie becomes less inclined to trust or support the vampires in her life. Initially Sookie allows Bill, to feed off of her in times of need. For example, when he wakes up after having involuntarily spent the day underground and discovers that his friends have been murdered in Dead Until Dark, she feeds him and lets him take out his anger and sadness sexually. Her willingness to let Bill have his way with her in this scene can be contrasted with another scene in Club Dead, the third novel in the series, when once again a distraught Bill feeds on her and tries to take sexual comfort, but this time Sookie rejects him because she cannot overlook the pain he has caused her.

Neither Bill nor Eric show any sign of bettering themselves because of Sookie's love. As their relationships progress, Sookie is repeatedly confronted by their vampire nature. At first, Sookie convinces herself that she can have a normal relationship with Bill and the end of their romance is connected to her disillusionment about this possibility. Eric is even less willing to apologize for his vampire nature; he tricks her into drinking his blood and sharing his bed. Their relationship is only possible when a bout of amnesia removes Eric's manipulative-vampire history from his memory. There are hints that Sookie reminds Eric of a different way of life, but he does not adjust his values to meet her expectations.

For fans, Sookie is the moral compass of the narrative, helping them accept the outcast vampires and later realize, perhaps, the folly of having done so. Not only do Sookie's efforts to help these vampires go un-rewarded, but it is even suggested that relations with them might corrupt her. Sookie is not alone; Buffy, Elena and Bella are also forced into morally dubious acts because of their love for vampires. Buffy is ashamed of her sexual relationship with Spike, declaring that it's killing her and attributing her loss of interest in being a superhero to the distraction of it. Elena pushes herself to become ruthless, to plot to kill vampires and to make choices she would not have considered before meeting Stefan. Bella makes the ultimate change for her man, though, by surrendering her human nature and becoming a vampire.

One could be forgiven for questioning whether these characters' faith in vampires has been misplaced. When viewed in the context of the Christian influences in Western culture, their tolerance makes sense. Christianity not only supports forgiveness in general, and further emphasizes supporting others as a traditionally female contribution to spiritual life. Female piety characterized by tolerance and acceptance might be extended too far when it is extended to vampires, who can need more than most, and take more than these women can give.

\section{From Absolute Morality to Relative Morality}

Vampire characters and the paranormal situations they engender can be vehicles for exploring the relativity of right and wrong in modern society. That is so evident in the general trajectory of these serialized vampire narratives. They develop from a situation of absolute to one of relative morals and all characters become more morally complex as these plotlines develop. This trajectory can make considerations of the Christian themes in these series problematic because, for example, as a series discards notions of absolute evil or complete redemption it becomes less able to consistently depict an idea like theosis.

Loss of consistent ethics is typical of melodramatic plot arcs and often necessary to enable the series to continue (Williamson, 2005, p. 43). Ambiguous characters in Buffy the Vampire Slayer, True Blood, The Vampire Diaries and Twilight films keep fans interested in the long plots of these serialized narratives, which can stretch over several years. To motivate story development, characters must dramatically change their behaviour, adding inconsistencies and complications to the way morality is constructed in these narratives. The 
moral world in Buffy the Vampire Slayer and The Vampire Diaries appears to have become more complex for precisely this reason. On the other hand, True Blood and the Twilight saga have moralities that remain more consistent throughout the series: Twilight communicates a near absolute morality from beginning to end and True Blood is set in a completely morally relative world. A comparison of these two series, therefore, illustrates how more relativistic moralities complicate the interpretation of Christian themes in all of these series.

In Twilight, Edward's benevolent character is well established early on in the story and Bella also has a consistently good character: together they are presented as a truly 'good' couple. Edward's unwavering commitment toward Bella is rivalled only by her commitment to him. Despite of much talk that he might hurt Bella, Edward does not. When Bella finds out about his true nature, her feelings remain constant. This steadiness of her inner moral compass is in fact so strong that withstands the trial of separation and even her own transformation into a vampire. The drama of this romance must come in the form of making it possible, helping other characters develop, and combating representatives of evil, mainly in the form of other vampires who do not restrict their diet as Edward and his family do.

Sookie, of True Blood, could not have more different romantic choices than Bella's. Even though both women begin their stories being courted by chivalrous vampires, Sookie takes many more dramatic twists and turns that can be, in part, explained by the moral relativity of her world. Her first love, Bill, seems to be very much like Edward but as the series progresses, and more aspects of Bill's character become known, it is no-longer clear whether his "good intentions" are, or ever were, genuine. Her second vampire love, Eric, is entirely unlike Edward from Twilight; indeed his only interest in the possibility that vampires may have an eternal soul is because he does not want to permit the souls of his enemies any rest (Ball, 2010).

Given her romantic lot in comparison to Bella, one might be inclined to pity Sookie. But, Sookie is no more ethically consistent than the vampires she loves (and sometimes hates). Constant Bella, in her absolutist world, is rewarded with the happy ending Romance genre fans expect. Sookie's ambivalence towards the vampires in her life, suggests that her story does not, and will not, conform to the expectations of the Romance genre. Sookie may not get, or want, a happy ending like Bella's.

The way that morality is constructed in these two narratives effects the plot presentation. The absolute morality and romance genre conventions of the Twilight saga undermine the storyline's dramatic potential. For example, Bella's transition to a vampire is a dramatic anti-climax. This event is much anticipated in the plot and full of potential pitfalls that go unexplored; instead she easily accomplishes the task. In another example, Edward's constancy of character renders his role less complex. In the series, since he is not truly a danger to Bella, he is soon reduced to the role of a typical, not supernatural, romance hero. The characterization of Bella and Edward in Twilight helps depict absolute evil as, although present, a less problematic concept. Fans can depend on the fact that Edward and Bella will not betray each other, and even that the vampires in Edward's family will be upstanding.

Morally consistent characters make less satisfying and effective drama because when the personalities of characters are set their range of potential actions. The absolute moral world also makes for less effective communication of theosis and kenosis for much the same reasons. Audiences like to see characters struggle, and when characters do not have ethical conflicts the plot is less engaging. Characters who are absolutely good offer up no conflict of will and no resistance to doing the right thing, a necessary component to analyses of how and why humanity struggles for salvation. More complex characters add suspense and realism to paranormal drama, making it both more dramatic and more ethically compelling. 
Moral relativity can be taken too far, however, as it sometimes seems to have been in the television series True Blood. Characters in this series act on impulse so often that they can appear to have no conscience (or conscious thought) at all. The world of True Blood can seem one where everything is permitted and very few characters are concerned with what is right, or how to be good. Moments when a moral choice is consciously made in this series are moving and memorable, but also few and far between. Complex characterizations help True Blood seem more realistic, but this "realism" is gained at the expense of moral consistency that could add significance to plot developments.

\section{Conclusion}

The above narratives fit a certain paradigm: A human female and a vampire male fall in love and they use that love to redeem him as a "main" point of the dramatic part of the series. They are all romantic narratives, and therefore able to demonstrate the redemptive features of love. It is interesting that in doing that, these stories explore the concept of self-sacrifice, most connected in Christian culture to the role model of Christ.

These are not primarily theological texts; they cannot forget their aim is to entertain and to some extent the outlandish moral dilemmas in these series are a literary product, to further the plot (O’Donnell, 2000, p. 204). Nevertheless, what matters to the characters in these narratives becomes important to the audience and therefore the philosophical or theological connotations of the story are relevant to readers and viewers. The Christian cultural context in which these narratives operate constructs characters' motives and potential plot developments. Even when mislabeled, these themes still reflect vestiges of prevalent moralities from the past and indicate topics of theological interest to modern audiences.

Most notably, these narratives indicate that understanding how to be good and the struggle to perform good acts are of great interest to contemporary audiences. The tendency in these series to develop ever more morally ambiguous and relative scenarios, when absolute moral rules restrict the dramatic needs of the plot, is not always unhelpful to the study of the philosophical and theological meaning of these narratives. By drifting into more realistic "morally relative" situations these narratives provide much to reflect upon, allowing readers and viewers to project their own interpretations into the vampire narrative.

\section{References}

Ball, Alan.(2010) "Evil is Going On” episode 36 of True Blood

Cassedy, Stephen.(2005). Dostoevsky’s Religion. (pp.150-153). California: Stanford University Press.

Clements, Susannah. (2011). The Vampire Defanged: How the Embodiment of Evil became a Romantic Hero. LOCATION: Brazos.

Gregory J Sakal, No Big Win: Themes of Sacrifice, Salvation, and Redemption , in James B South ed. Buffy the Vampire Slayer and Philosophy (Open Court, 2003)

Mark, O’Donnell. (2002). Fall, Redemption and Immortality in the Vampire Mythos, Theology 103/813. $204-212$.

Mark, S M Scott Jason Zuidema.(2010). Religious Studies and Popular Fiction: What Does Dan Brown Have to Do With the Ivory Tower? , Journal of Religion and Popular Culture 23/3 (Fall 2011) 372-381.

Peter, Brooks.(1995). The Melodramatic Imagination: Balzac, Henry James, Melodrama, and the Mode of Excess. New Haven, CT: Yale University Press.

Stoker, Bram. (1993). Dracula. Ware, Hertfordshire: Wordsworth Classics. Original pub date 1897 how do I include this? Williamson, Milly. (2005). The Lure of the Vampire: Gender, Fiction and Fandom from Bram Stoker to Buffy. Columbia: Wallflower Press.

Zanger, Jules. (1997). Metaphor into Metonymy: The Vampire Next Door. In Blood Read: the Vampire as Metaphor in Contemporary Culture edited by John Gordon and Veronica Hollinger (pp. 17-26). Pennsylvania: University of Pennsylvania Press. 